\title{
3 Research Square \\ Bilateral Control of a 2-DOF Teleoperated \\ Manipulator Using UDP Scheme
}

\author{
Magdi Mohsen \\ Assiut University \\ khalil Ibrahim ( $\nabla$ khalil.ibrahim@aun.edu.eg ) \\ Assiut University https://orcid.org/0000-0002-4234-6603
}

\section{Original Article}

Keywords: teleoperation, bilateral, position tracking, model identification, Least-Squares, FLC, PID, network time delay, UDP, MATLAB, SIMULINK

Posted Date: April 7th, 2021

DOI: https://doi.org/10.21203/rs.3.rs-309336/v1

License: (c) (1) This work is licensed under a Creative Commons Attribution 4.0 International License. Read Full License 


\section{Abstract}

In this paper, a workspace-control system was developed to deals with the problem of position-tracking of bilateral teleoperated two degrees of freedom manipulators, and aid the human operator in driving and controlling the slave robot that performs critical and difficult tasks such as under water works. The developed system consists of, "JUPITER XL SCARA" robot as a slave manipulator with only the first two links activated, a wireless User Datagram Protocol (UDP) network, and PC as a master controller. The system model parameters identified using the Least-Squares method. A PID and FLC controllers with different input signals were applied to the system. It was proved experimentally and by simulation on Matlab that the FLC gave a better performance than the PID controller. The two parallel loop subroutine technique proved a great enhancement to the system performance as it decreased the total delay time in the system to almost 25 milliseconds.

\section{Full Text}

This preprint is available for download as a PDF.

\section{Figures}

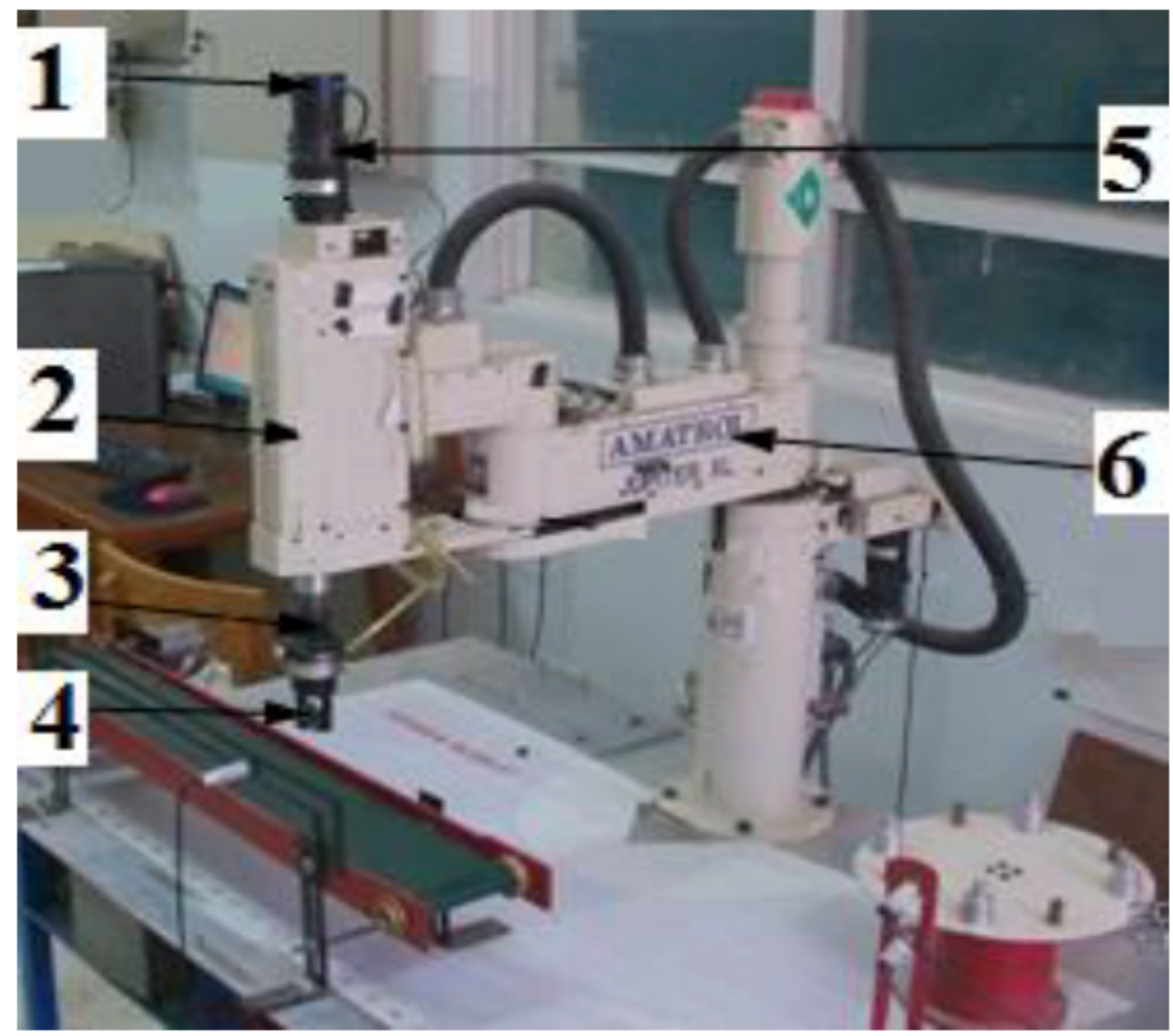


Figure 1

JUPITER XL SCARA robot. (1. Optical encoder, 2. Link two, 3. Link three, 4.Gripper, 5. DC Motor, 6. link one )

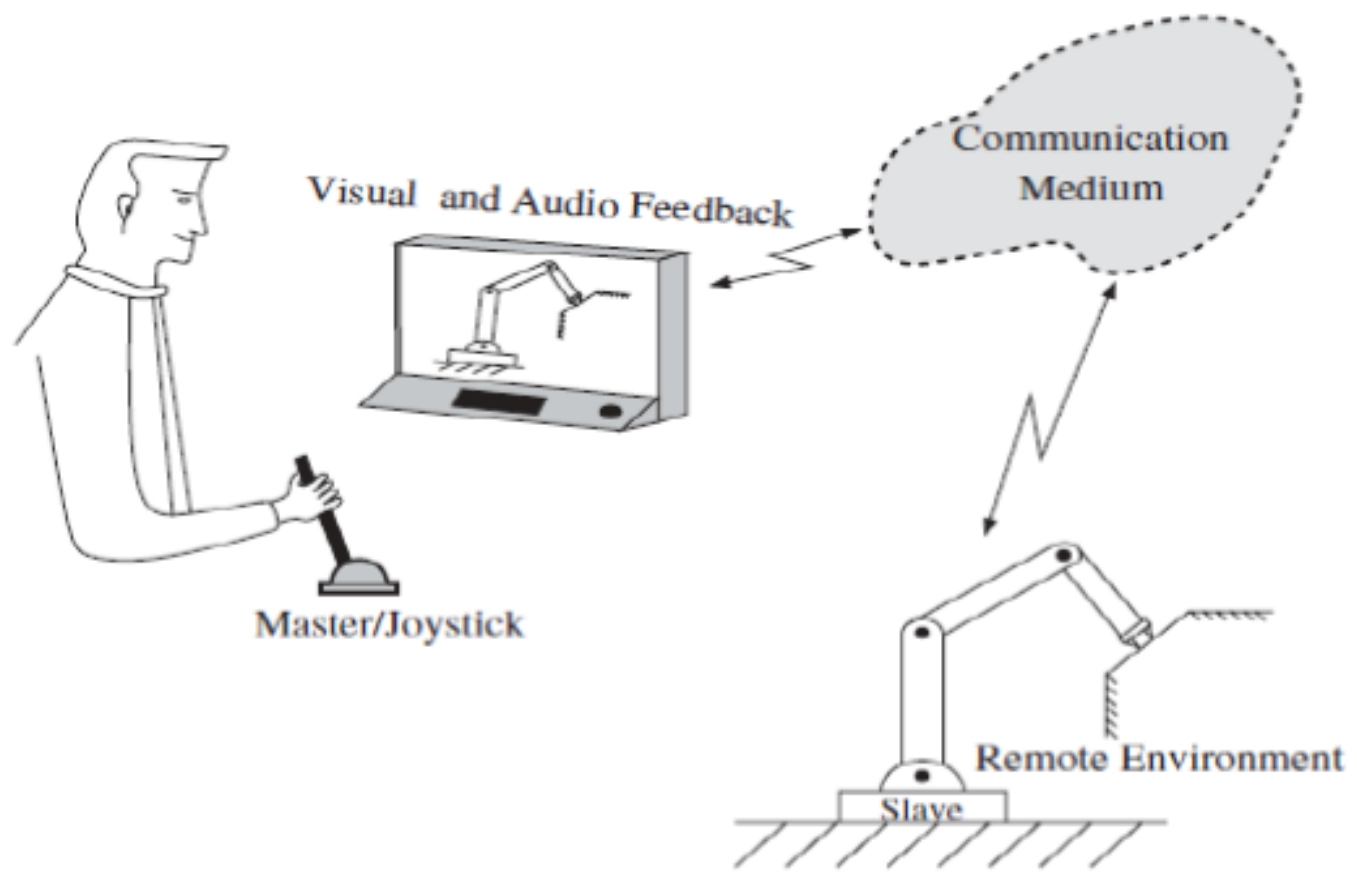

Figure 2

The workspace control system

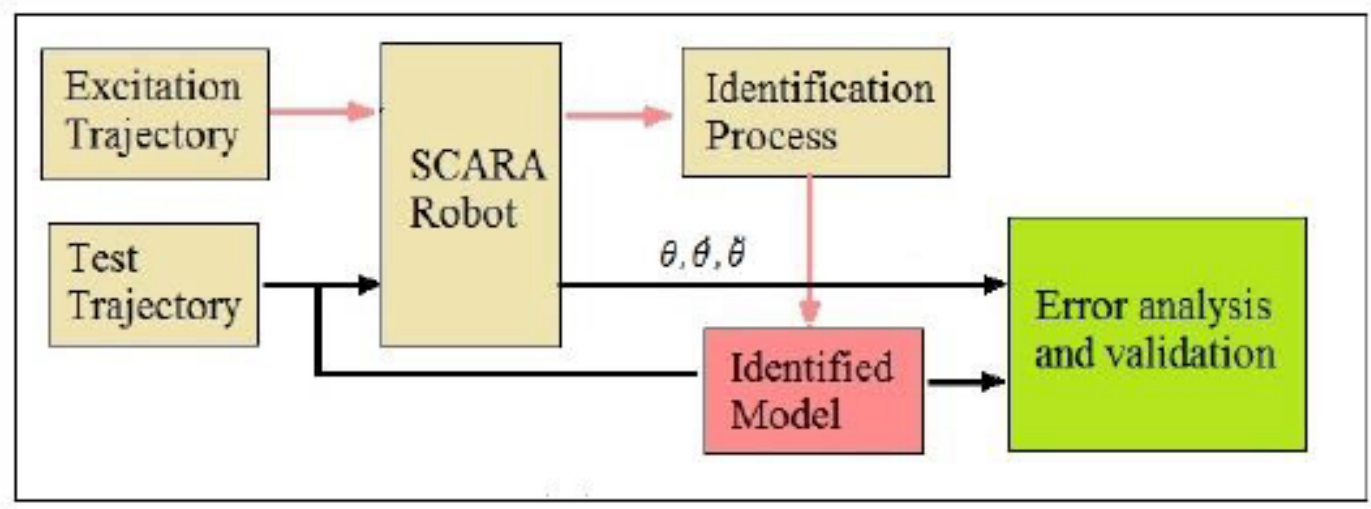

Figure 3

Model identification validation scheme. 


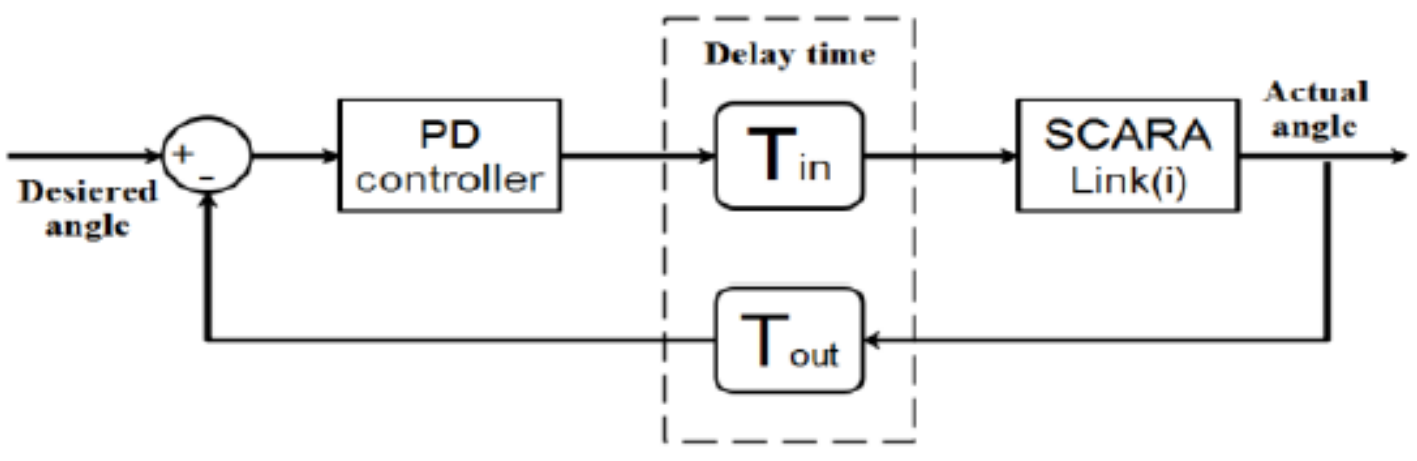

Figure 4

Bilateral teleoperated PD controller block diagram. 




Figure 5

First scheme software architecture 


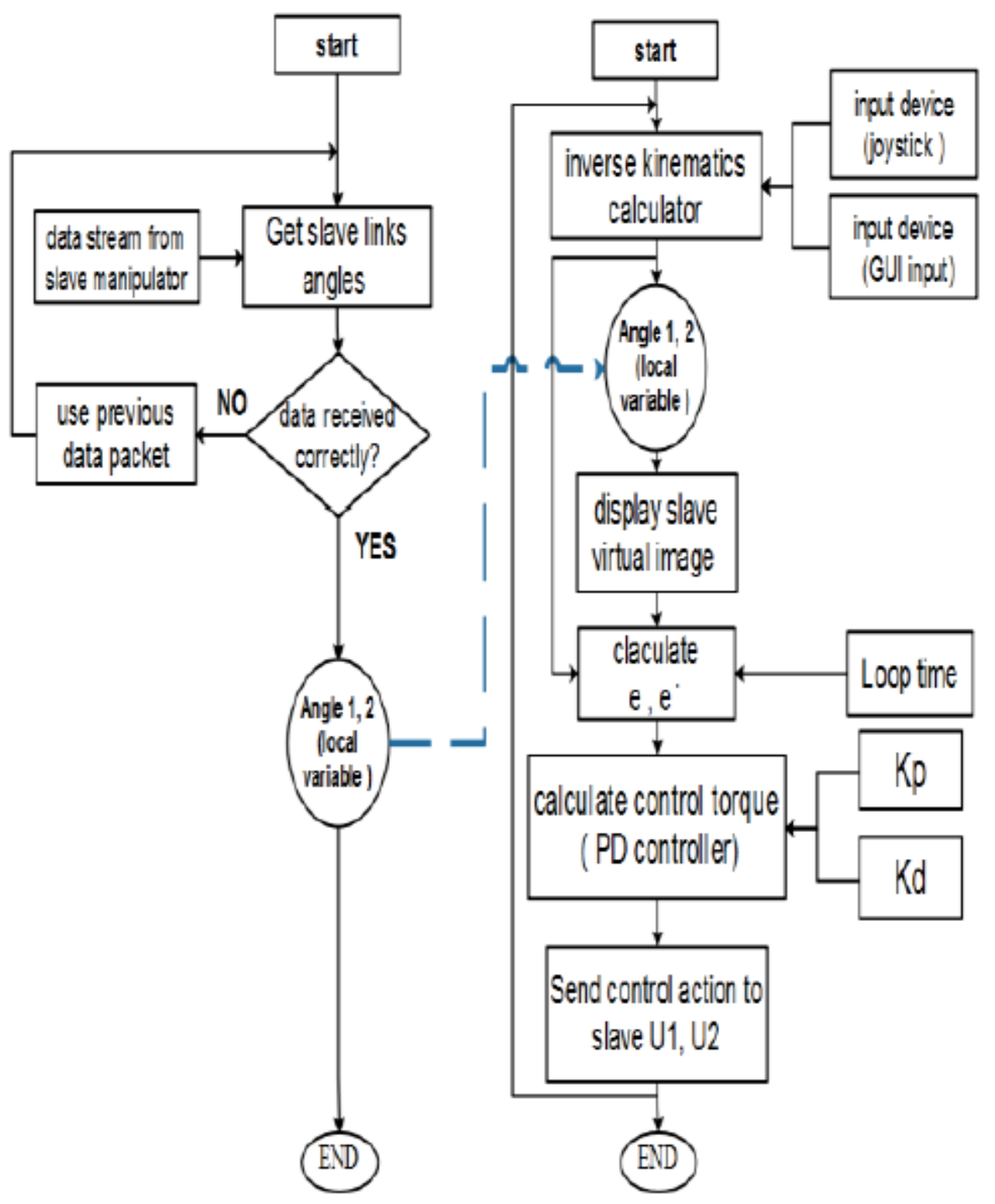

Figure 6

Second scheme software architecture

Figure 7 was not provided with this version of the manuscript.

Figure 7

Figure 7 was not provided with this version of the manuscript. 


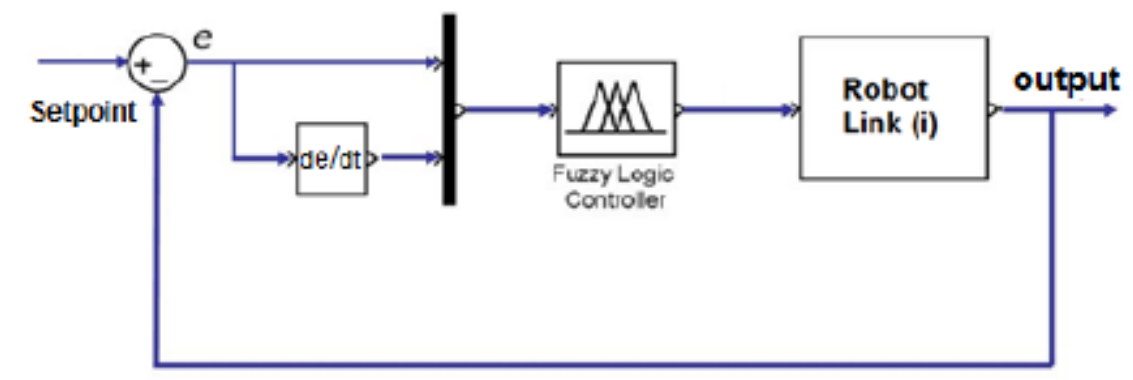

Figure 8

The fuzzy controller block diagram.

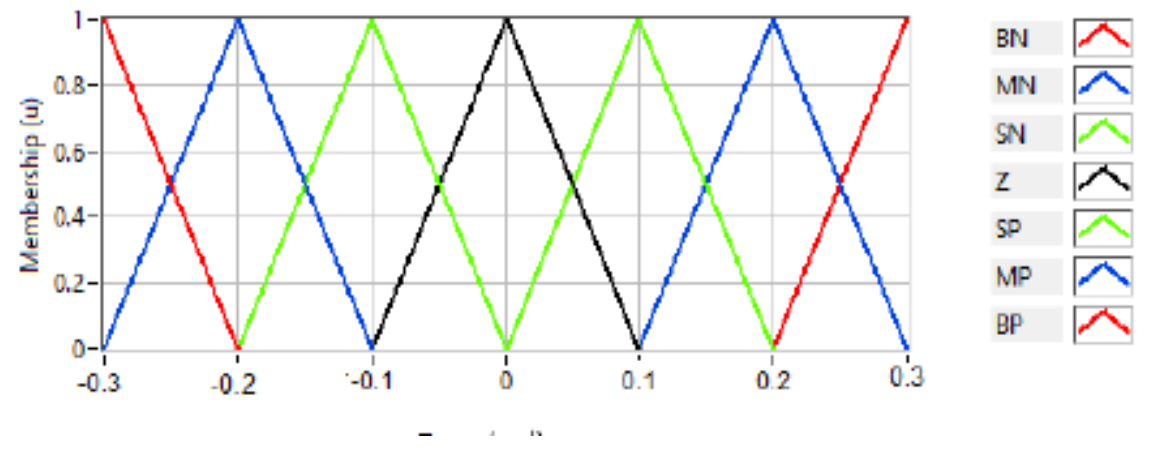

Figure 9

Error membership functions of joint $(1,2)$

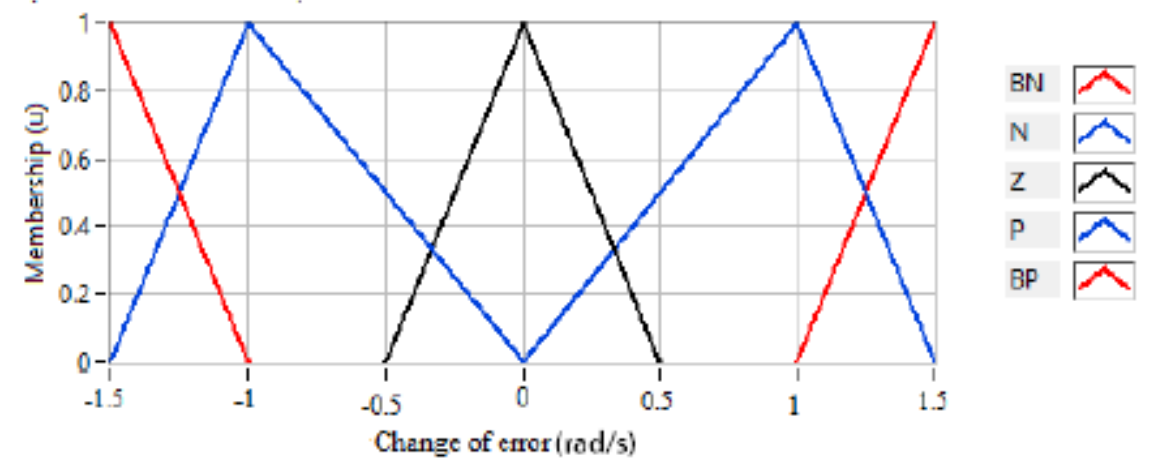

Figure 10

Change of error membership functions of joint $(1,2)$ 

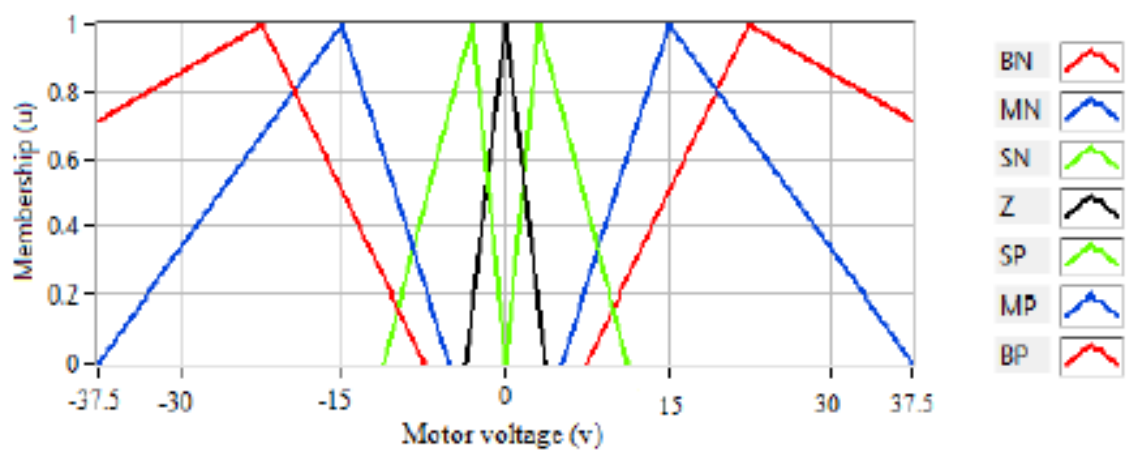

Figure 11

Output membership function of joint 1 .
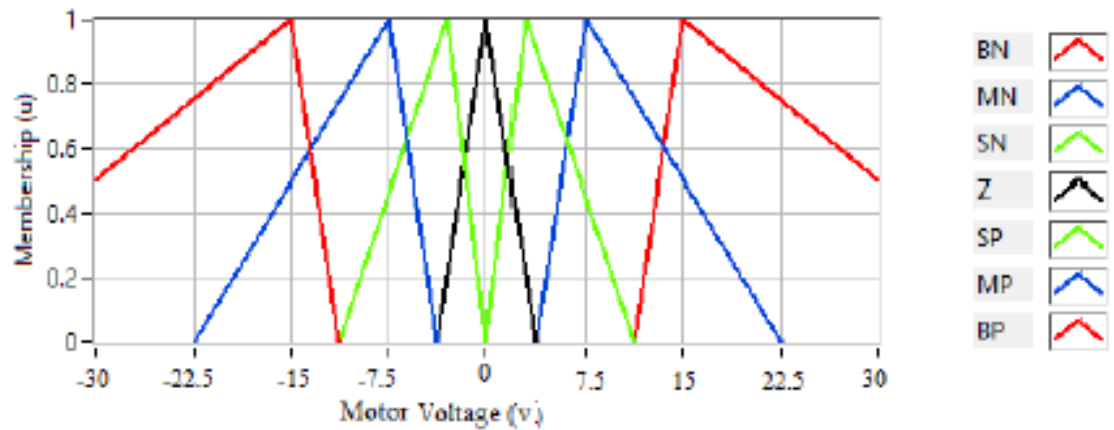

Figure 12

Output membership function of joint 2 .

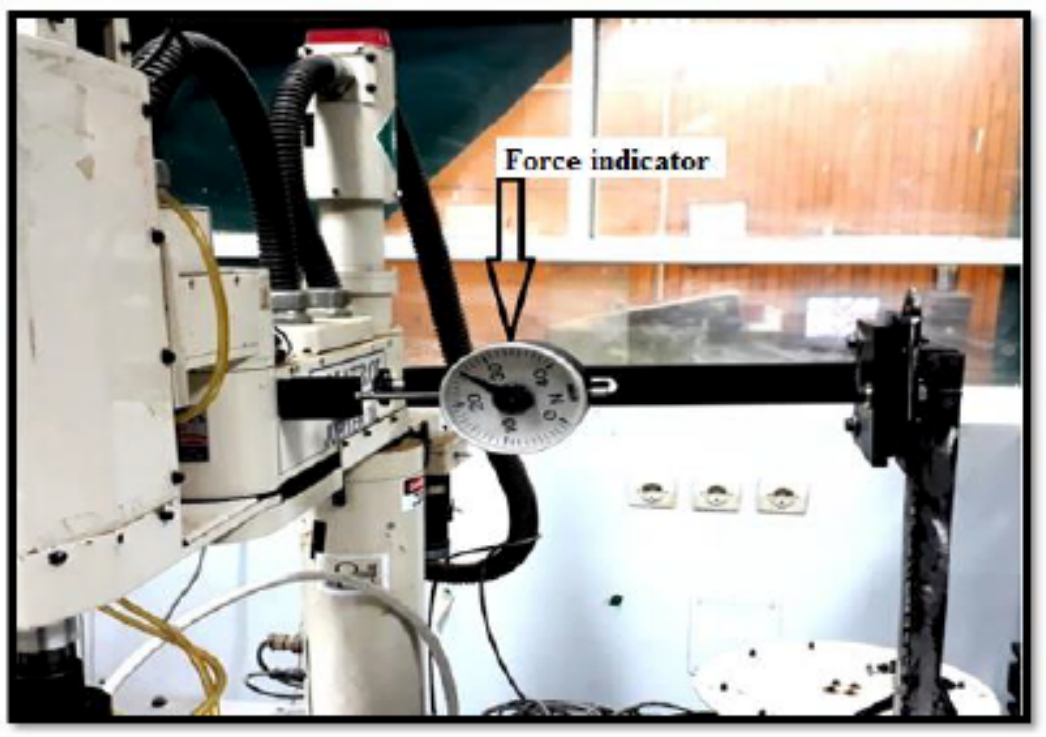

Figure 13 
Force measurement.

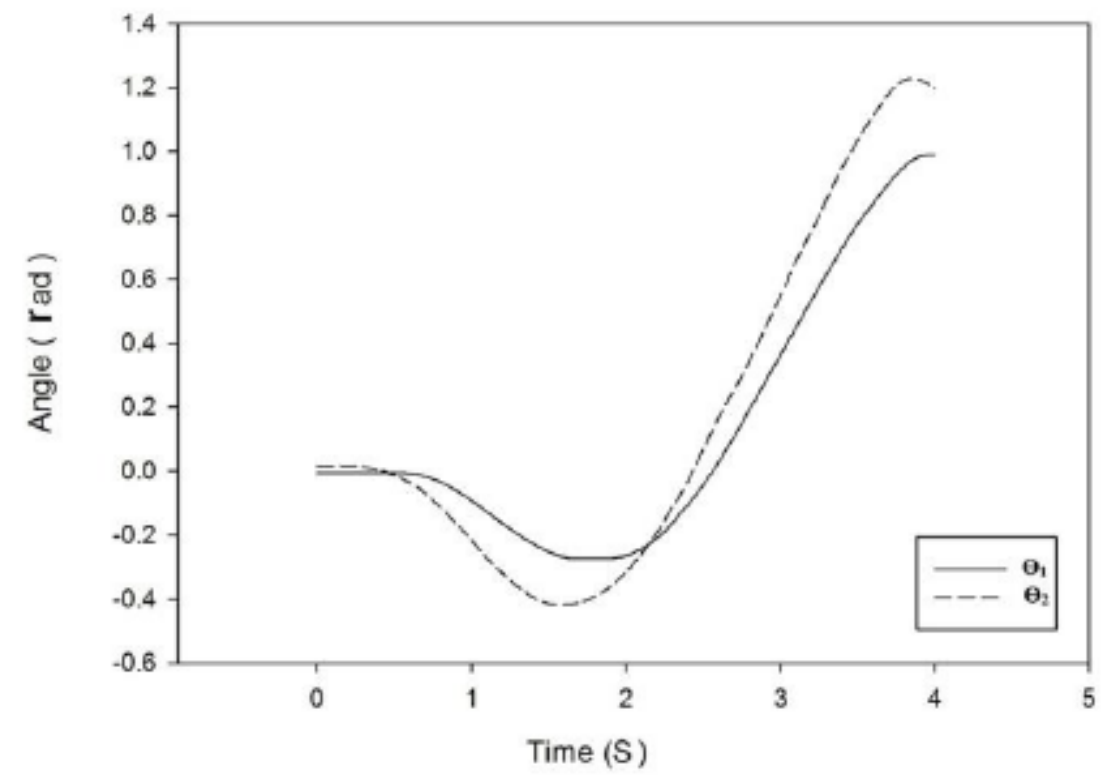

Figure 14

Change in joint position for $₫ 1$, and $\varangle 2$ with time.

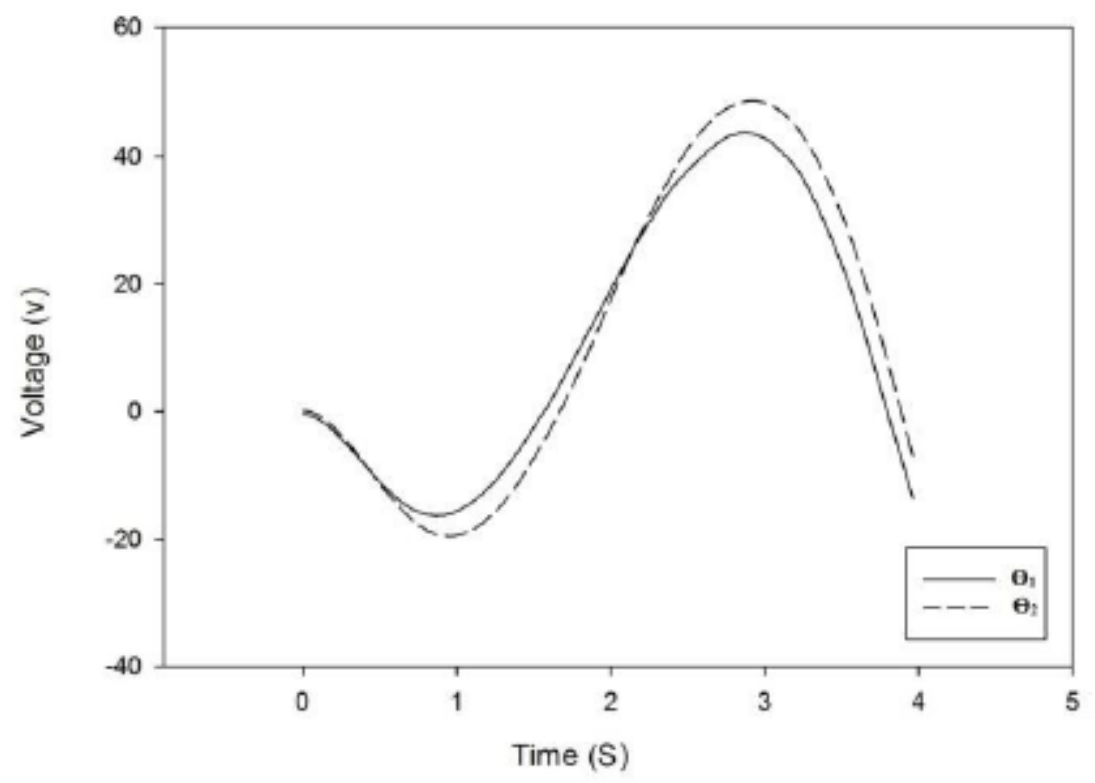

Figure 15

The input voltage for $\otimes 1$, and $₫ 2$ with time. 


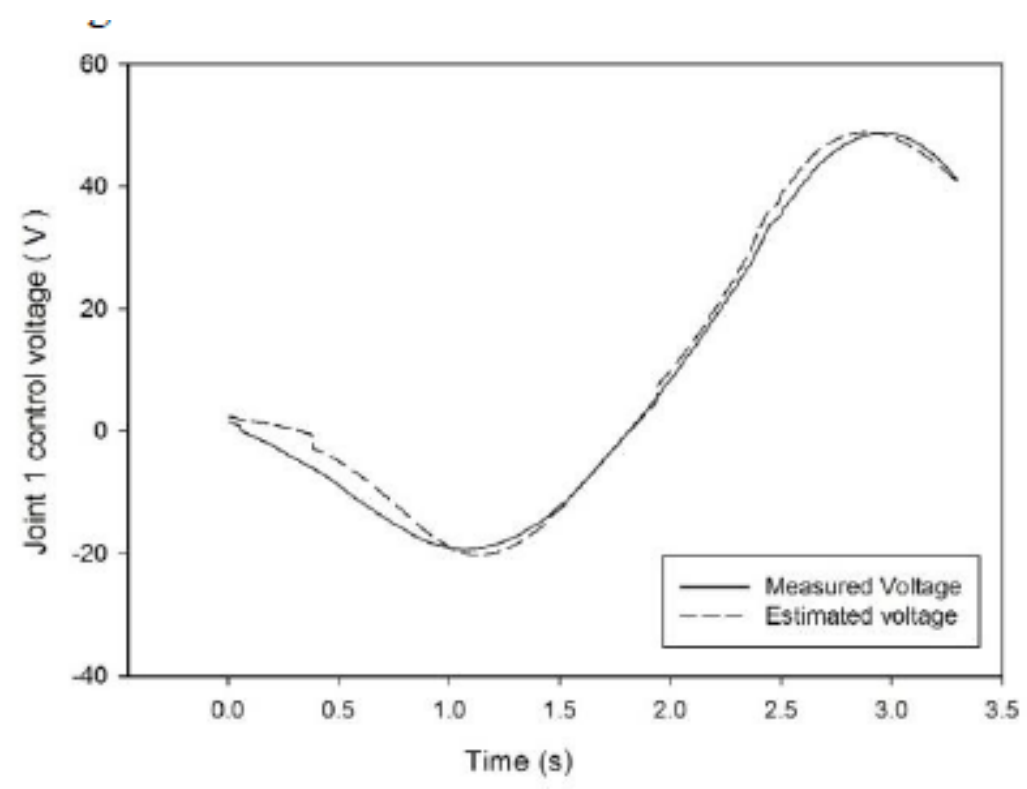

Figure 16

Measured voltage and estimated voltage of joint 1 with time for the test trajectory.

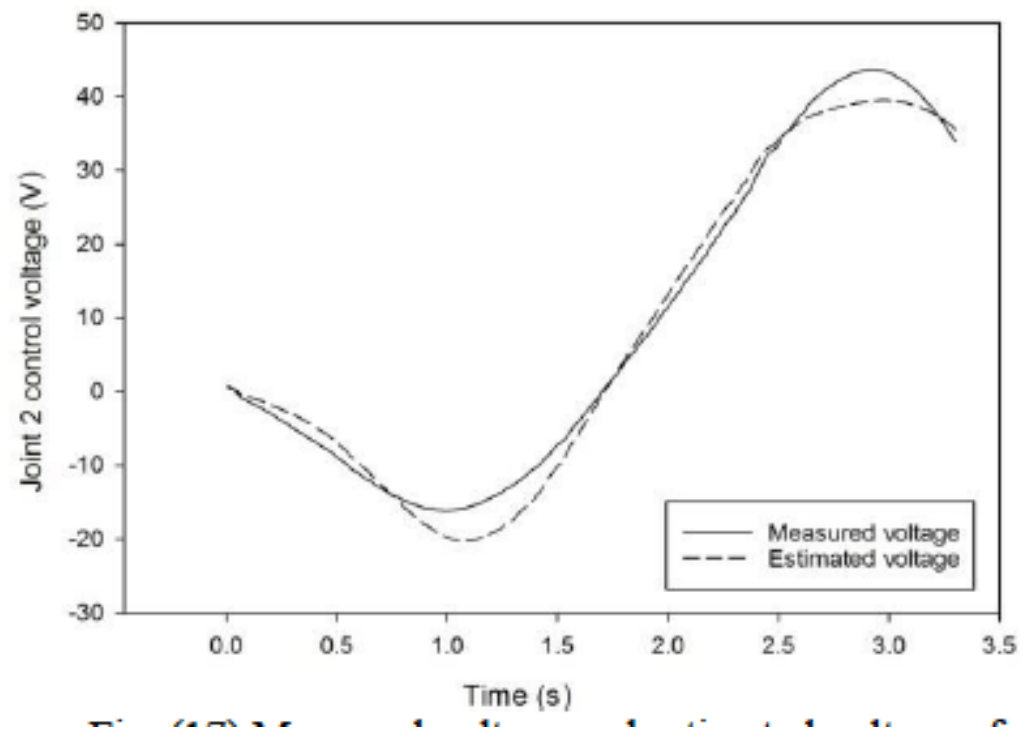

Figure 17

Measured voltage and estimated voltage of joint 2 with time for test trajectory. 


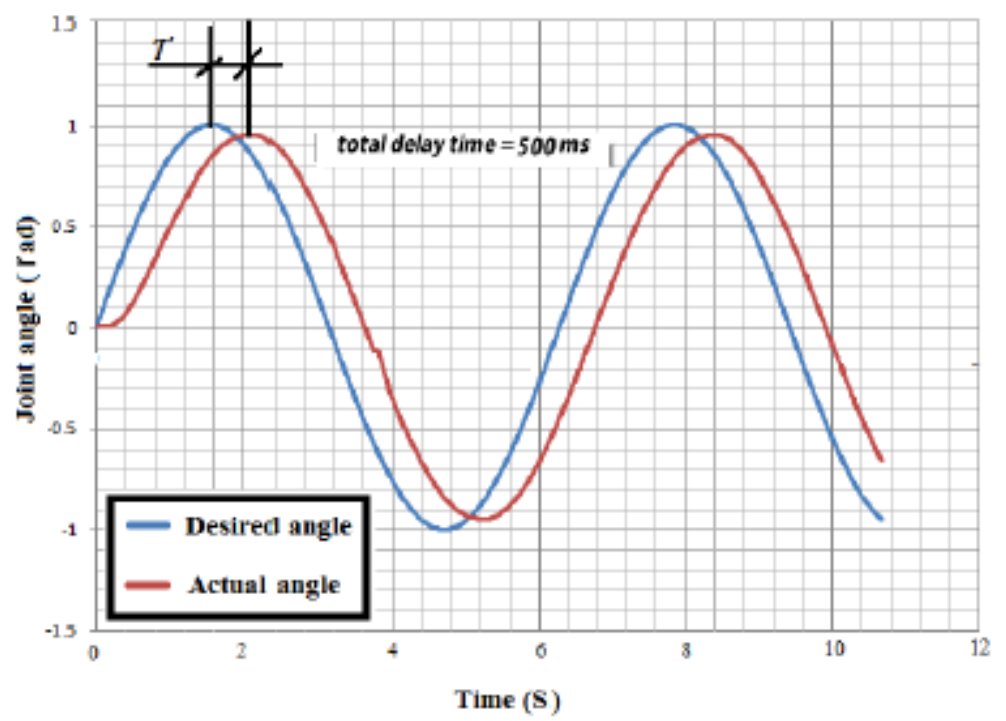

Figure 18

The first scheme of trajectory tracking of the PD controller

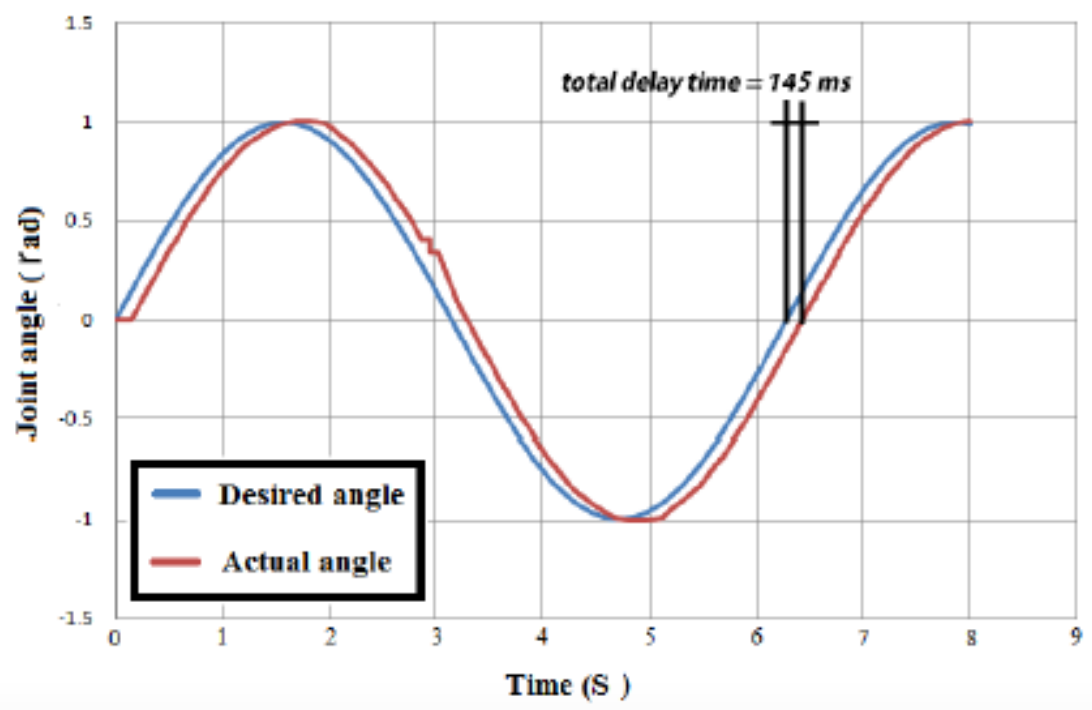

Figure 19

The second scheme of trajectory tracking of the PD controller 


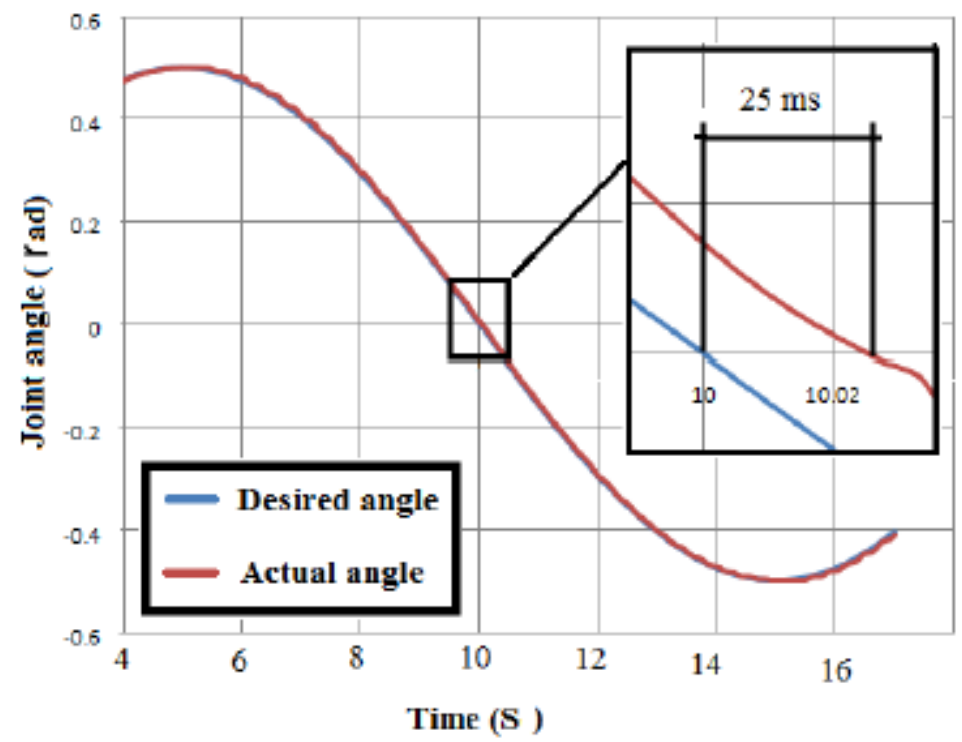

Figure 20

The system total delay time while applying a FLC.

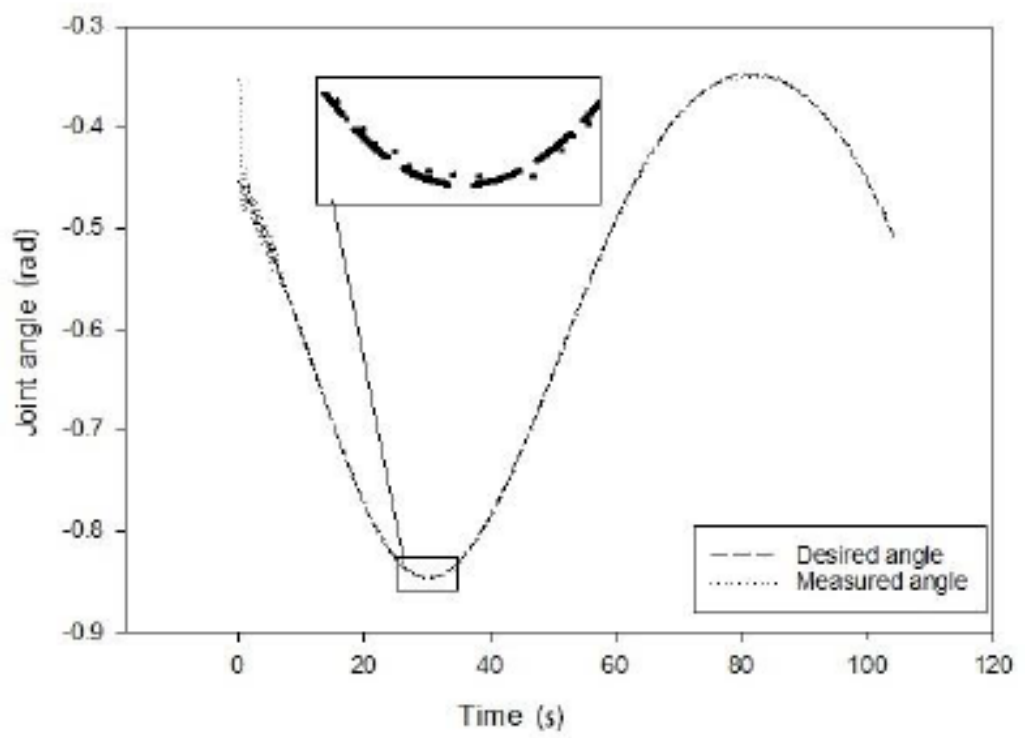

Figure 21

Joint 1 measured angle due to circle input while using PID controller. 


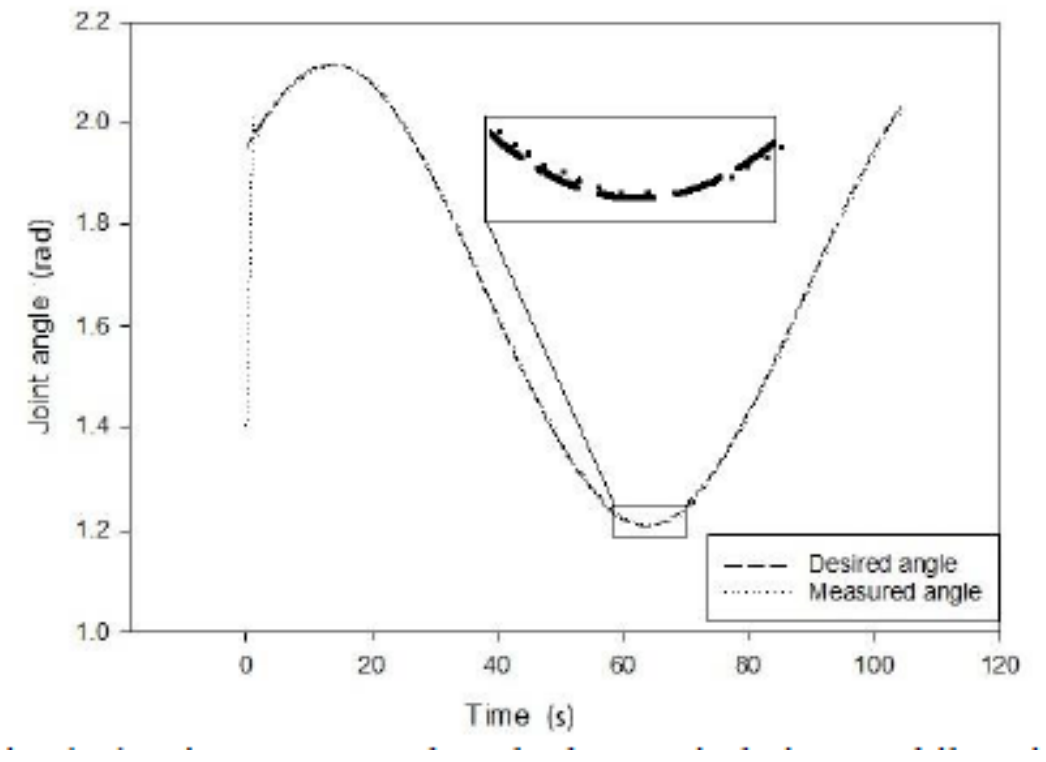

Figure 22

Joint 2 measured angle due to circle input while using PID controller.

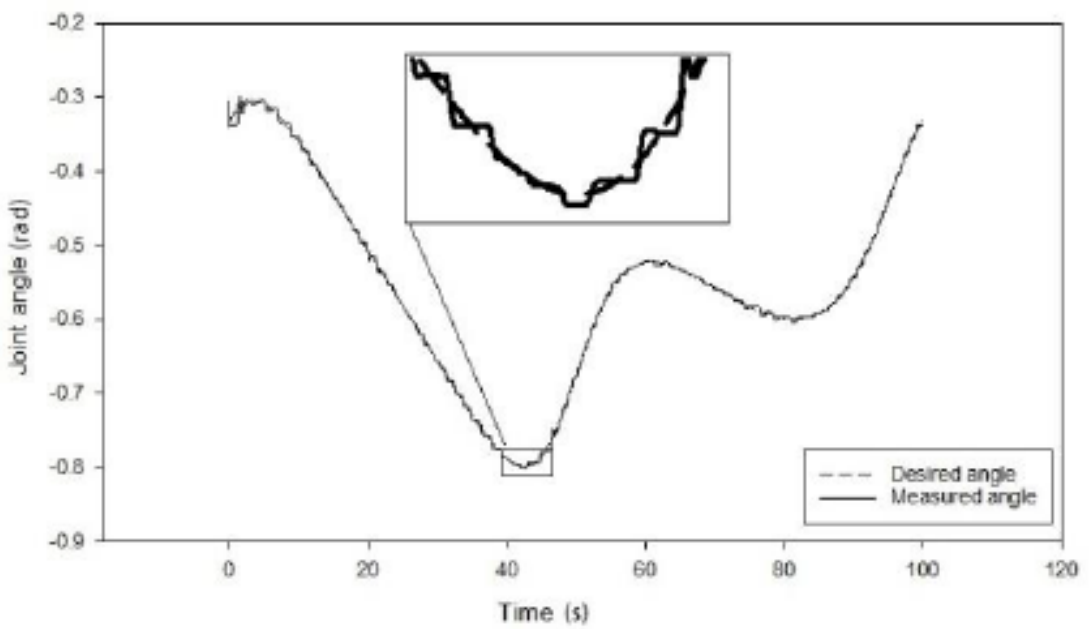

Figure 23

Joint 1 measured angle due to lemniscate input while using PID controller. 


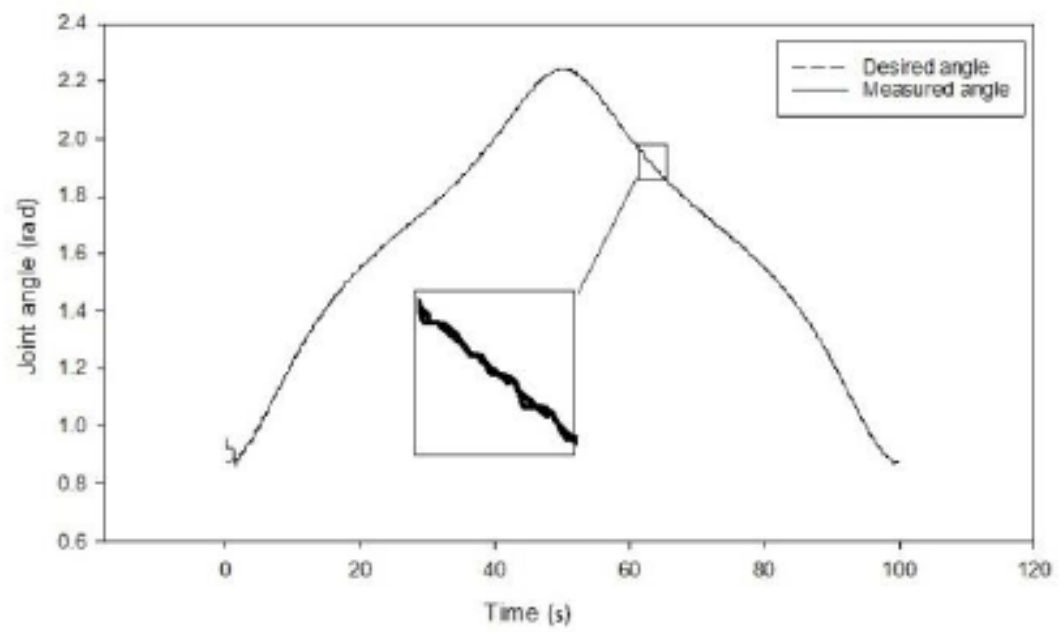

Figure 24

Joint 2 measured angle due to lemniscate input while using PID controller.

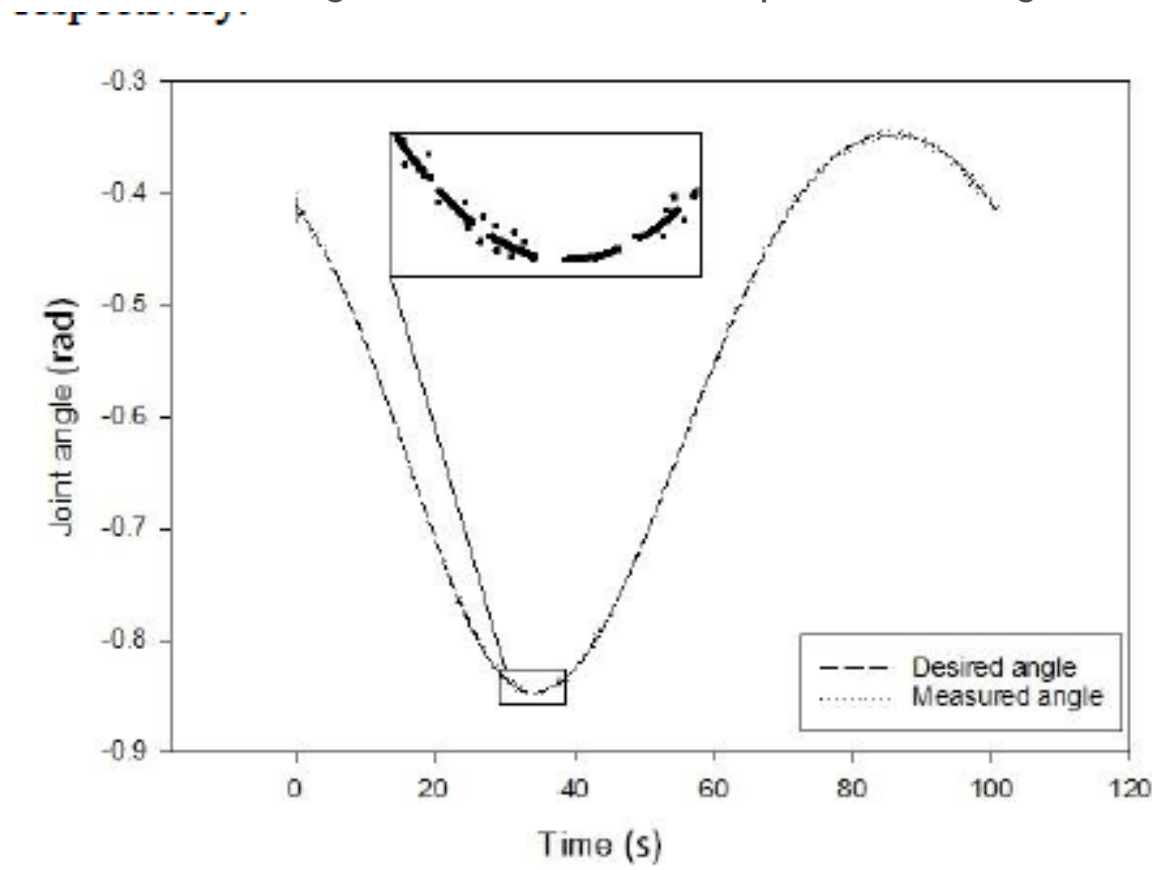

Figure 25

Joint 1 measured angle due to circle input while using FLC controller. 


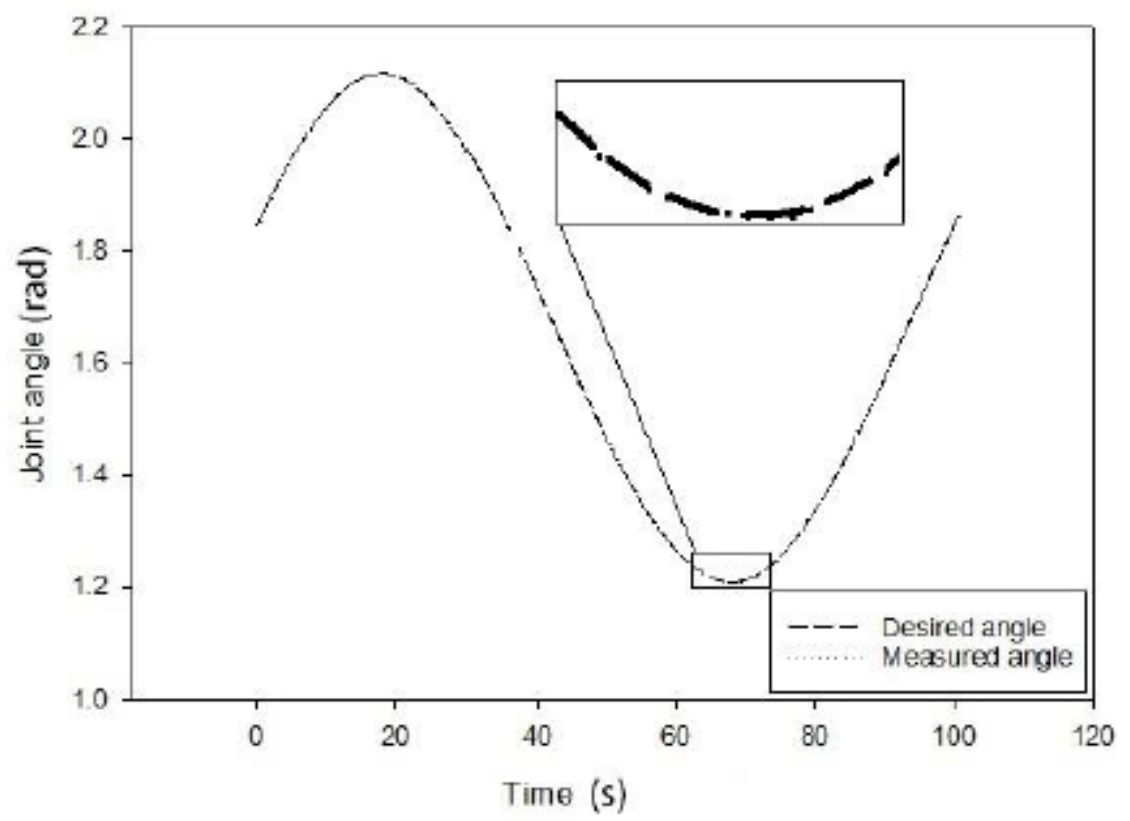

Figure 26

Joint 2 measured angle due to circle input while using FLC controller.

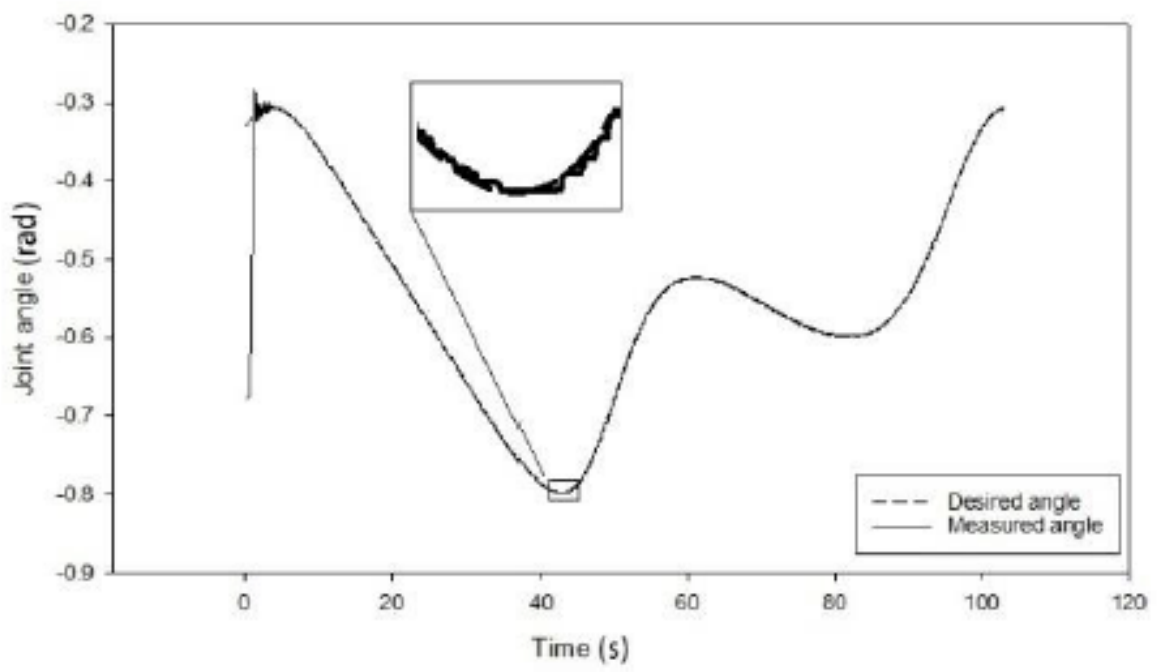

Figure 27

Joint 1 measured angle due to lemniscate shape input while using FLC controller. 


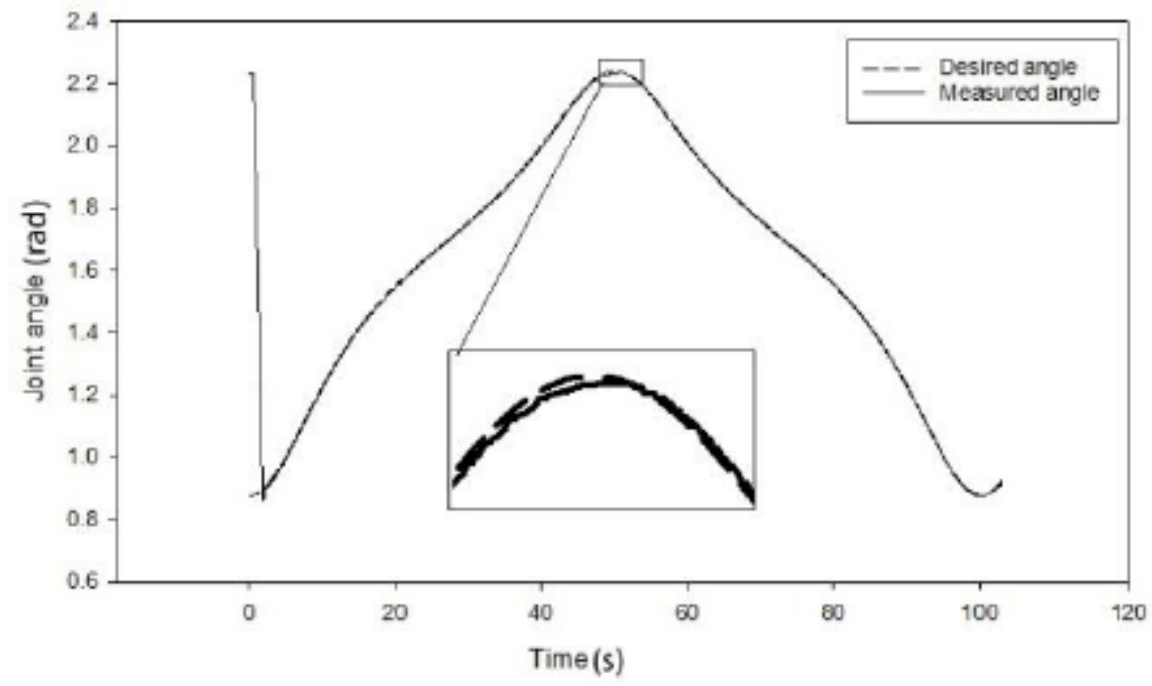

Figure 28

Joint 2 measured angle due to lemniscate shape input while using FLC controller.

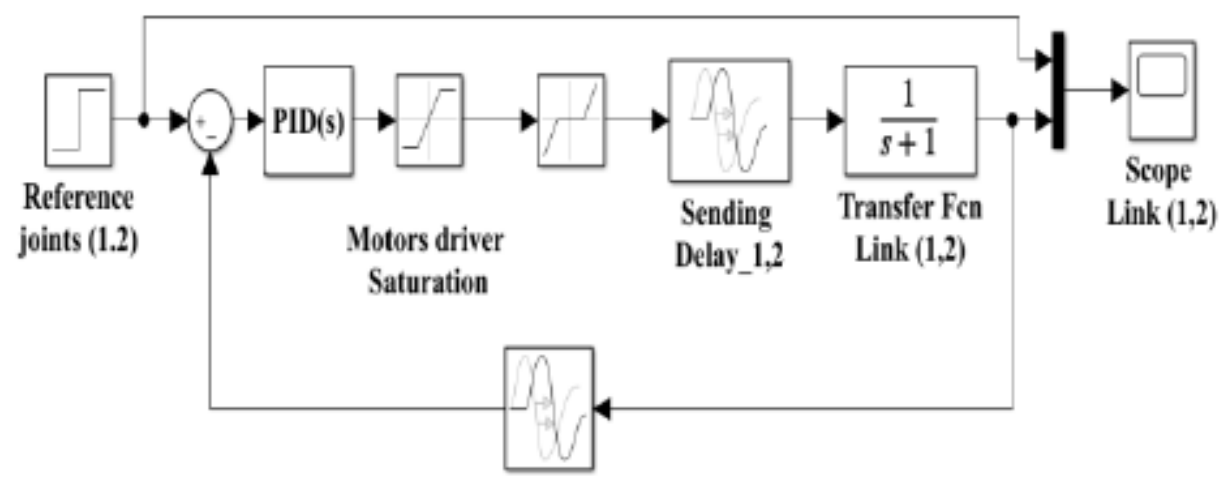

Reciving

Delay_1,2

Figure 29

Simulink model for PID controller 


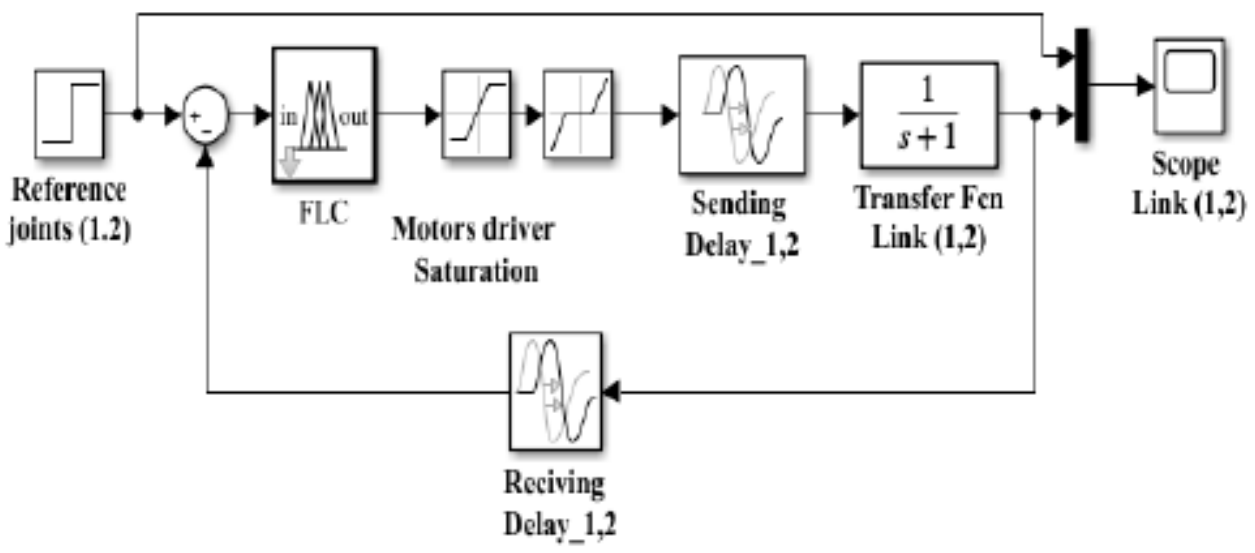

\section{Figure 30}

Simulink model for fuzzy logic controller.

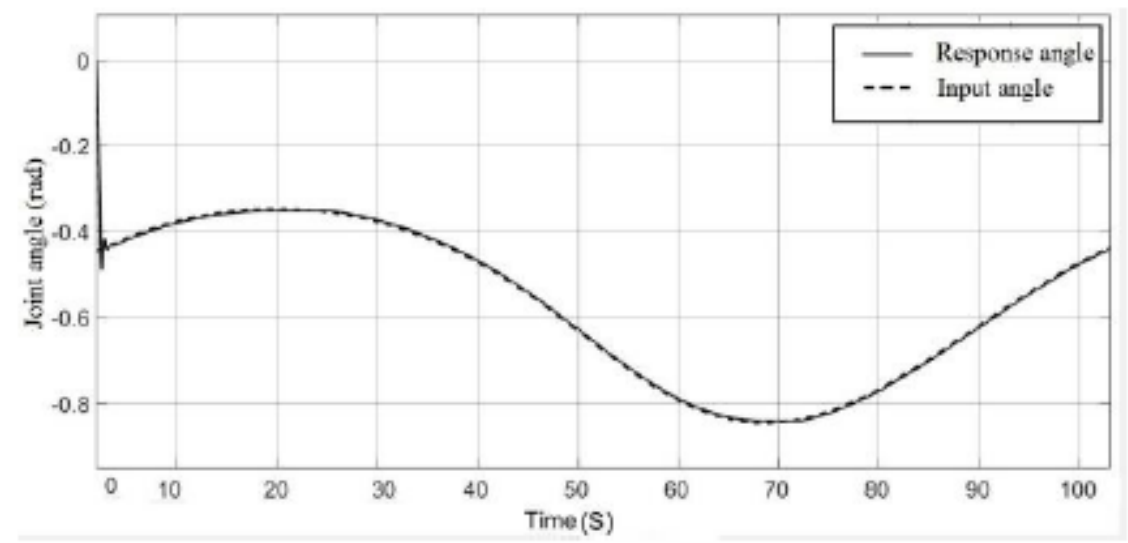

\section{Figure 31}

Joint 1 angle simulated response due to circular input obtained using PID controller.

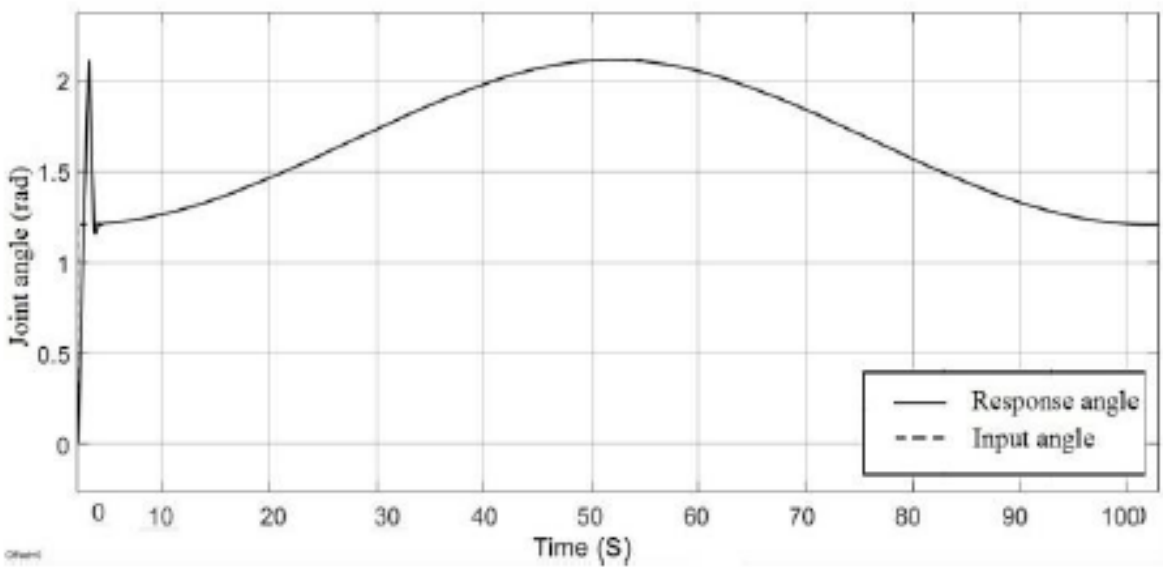


Figure 32

Joint 2 angle simulated response due to circular input obtained using PID controller.

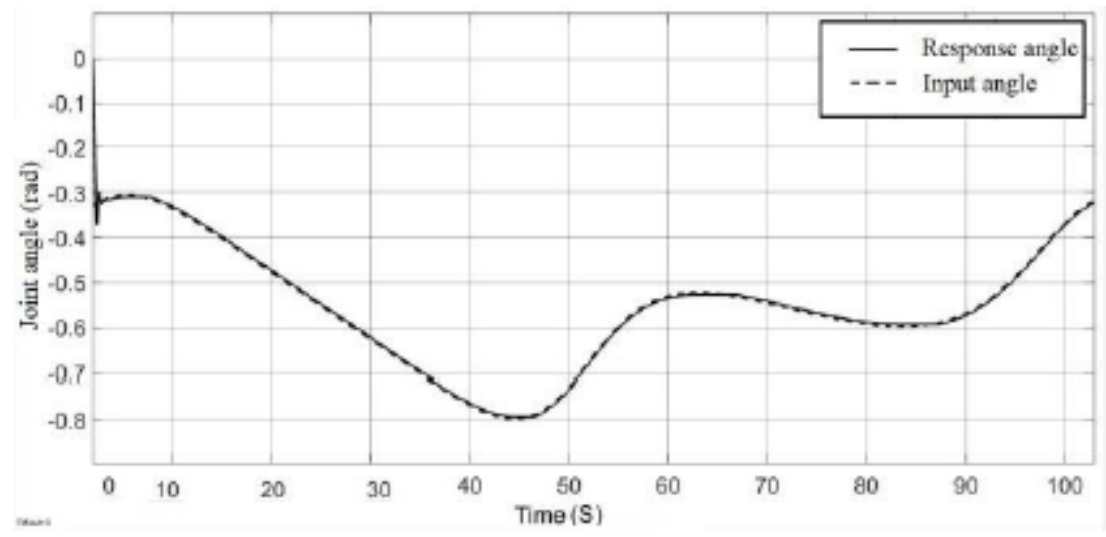

\section{Figure 33}

Joint 1 angle simulated response due to lemniscate input obtained using PID controller.

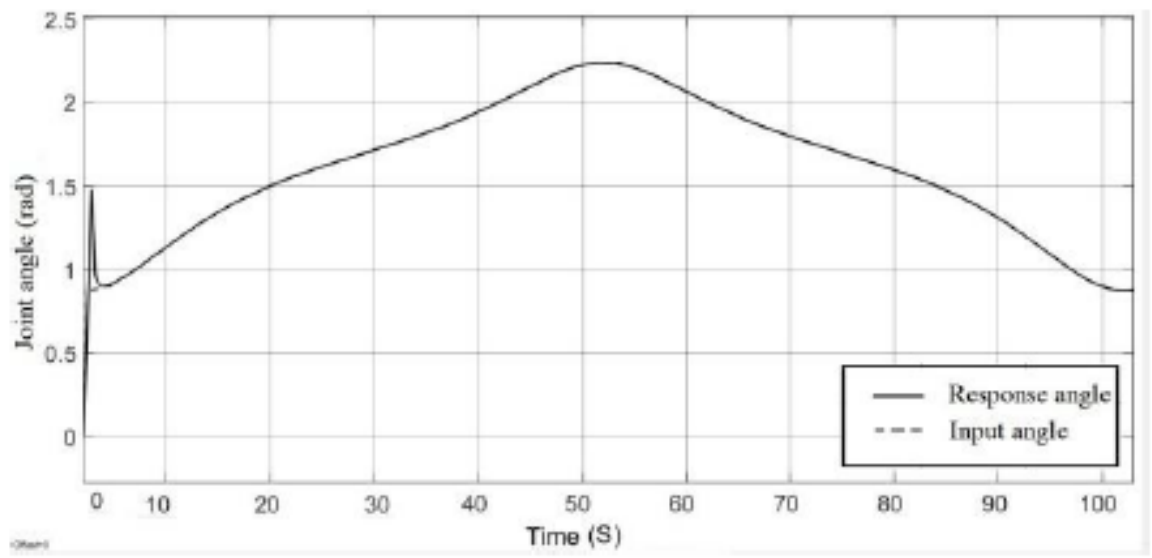

\section{Figure 34}

Joint 2 angle simulated response due to lemniscate input obtained using PID controller. 


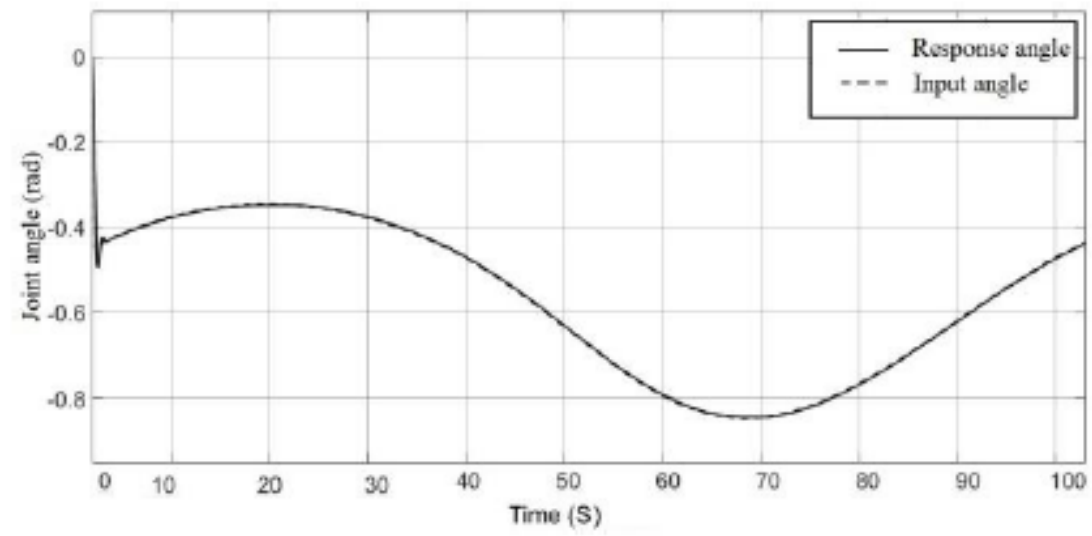

Figure 35

Joint1 angle simulated response due to circle input obtained through the FLC control method.

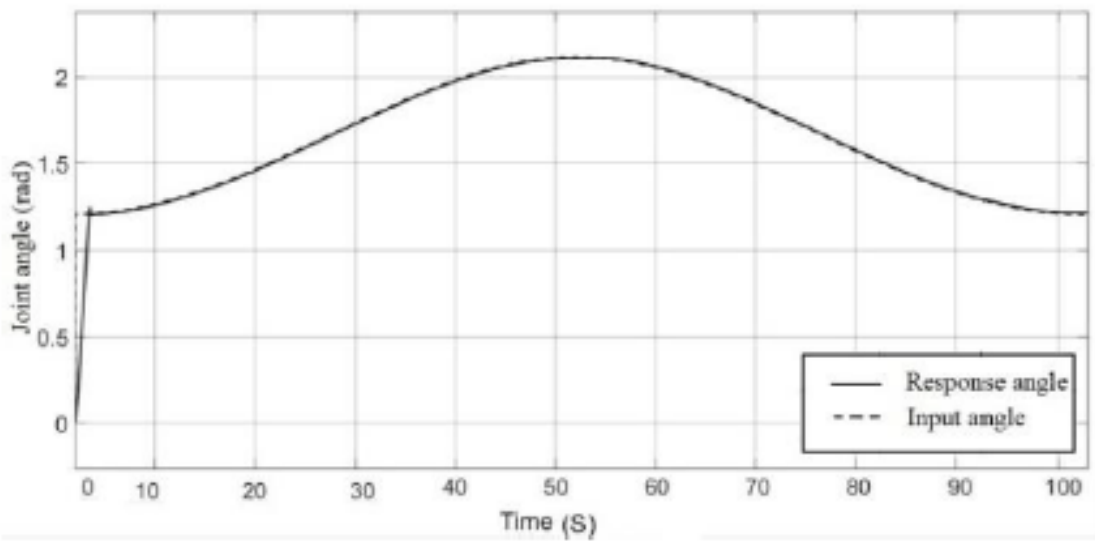

Figure 36

Joint2 angle simulated response due to circle input obtained through the FLC control method.

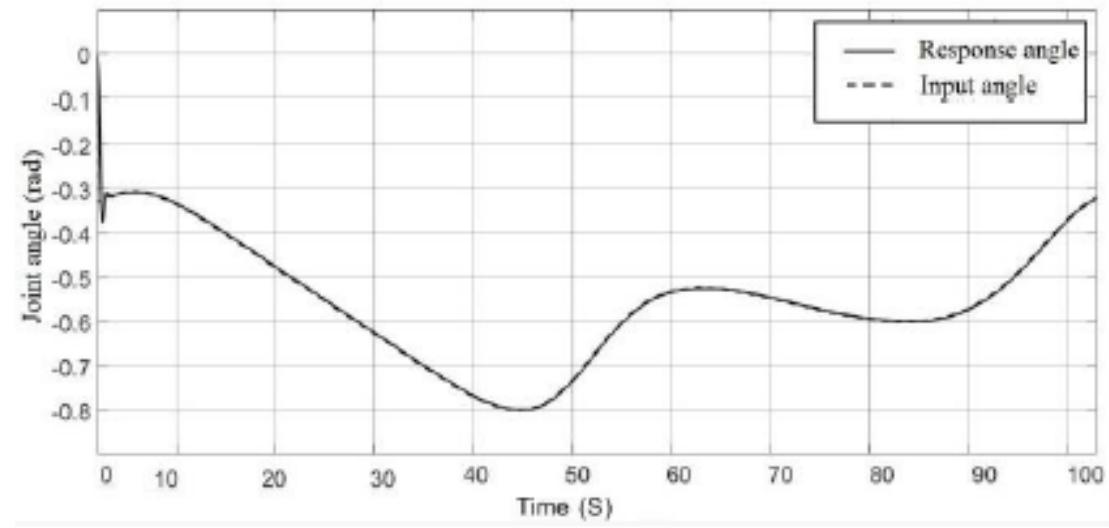

Figure 37 
Joint 1 angle simulated response due to lemniscate shape input obtained through the FLC control method.

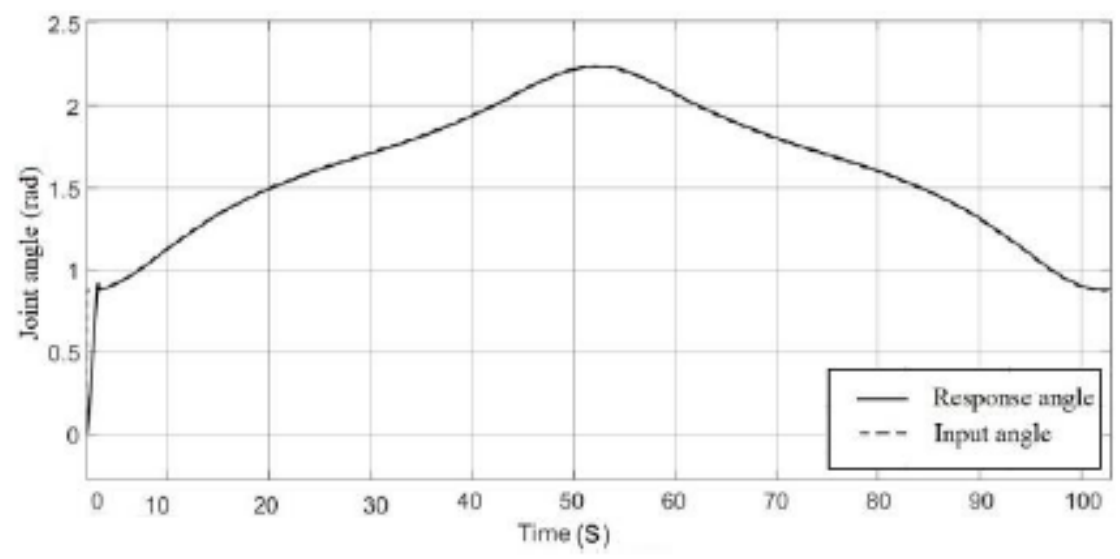

Figure 38

Joint2 angle simulated response due to lemniscate shape input obtained through the FLC control method.
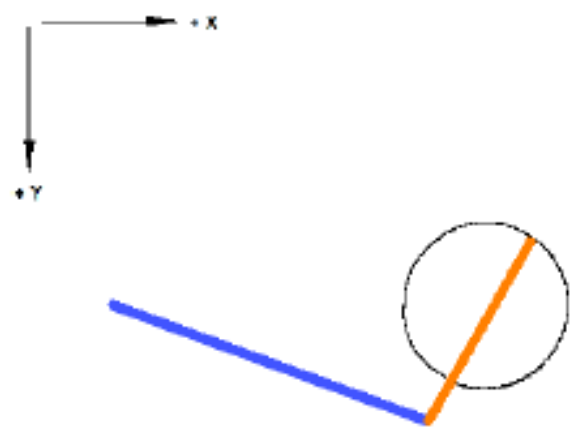

a) Circle shape input.
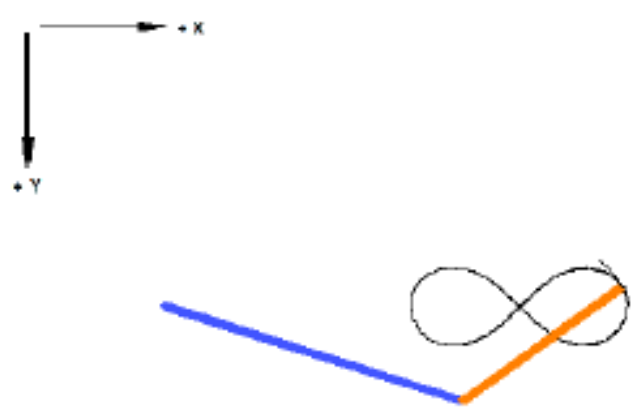

Figure 39

Endeffector of SCARA robot with circle and lemniscate shape inputs. 


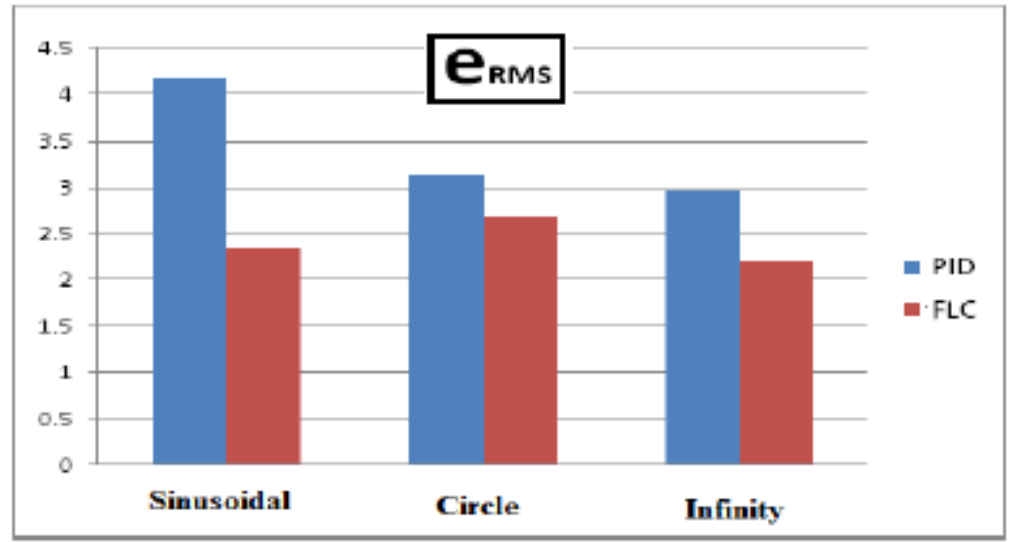

Figure 40

Comparison of Joint1 experimentally response eRMS for sinusoidal, circle, and lemniscate shape inputs using PID and FLC.

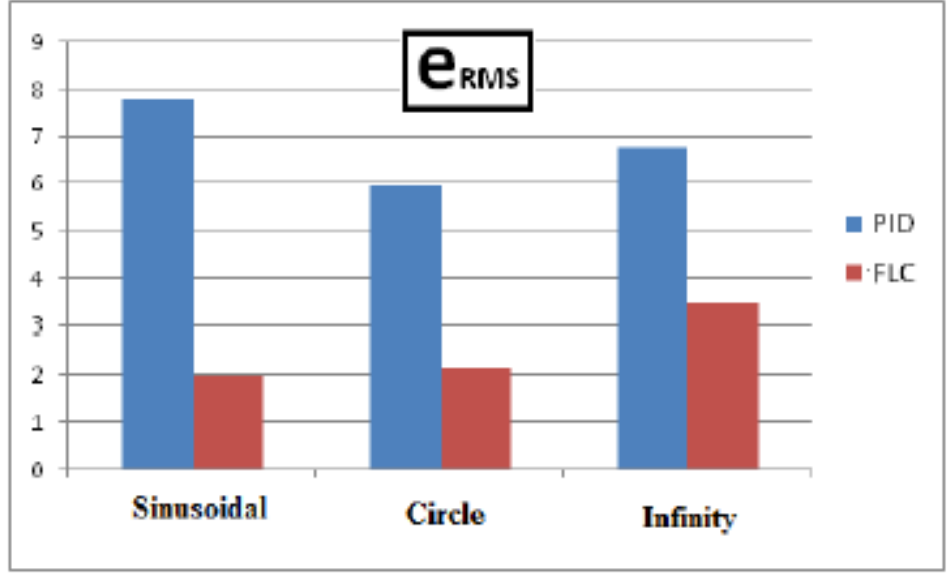

\section{Figure 41}

Comparison of Joint2 experimentally response eRMS for sinusoidal, circle, and lemniscate shape inputs using PID and FLC. 